\title{
Sobre os problemas da aprendizagem da Química no último ano de ensino secundário e no $1 .^{\circ}$ ano do ensino superior

\author{
Victor M. S. Gil a
}

Um dos painéis de discussão no último Encontro da Sociedade Portuguesa de Química, realizado em Braga, tinha por tema "Interface do ensino da Química entre os níveis secundário e terciário". Tomando o vocábulo "interface", não como "interfície", sem espessura e, quiçá, sem campo para discussão, mas como "interfase" constituída pelo actual último ano de ensino secundário (12. ${ }^{\circ}$ ano de escolaridade) e pelo $1 .^{\circ}$ ano do ensino superior, preparei, para esse painel, uma lista que sistematizava defeitos associados ao ensino-aprendizagem da Química naqueles anos, reunia as razőes próximas subjacentes e alinhava propostas de medidas correctivas a tomar.

É este tema que aqui se retoma, numa análise que se deseja serena e completa, pois é altura de redimensionar e integrar as críticas, mais ou menos apaixonadas e parciais, úteis numa certa fase.

Desde logo deve reconhecer-se que, se alguns dos problemas são específicos da Química, outros são comuns a várias disciplinas. E, também, que algumas das críticas feitas, designadamente ao $12 .^{\circ}$ ano, não podem ignorar os defeitos aliados ao ensino-aprendizagem da Química e de outras áreas do conhecimento, incluindo a Matemática e a Língua Portuguesa (compreensão e expressão) nos anos a montante no ensino secundário. Começando por reconhecer a quase inexistência de cursos secundários profissionalizantes em que a Química intervenha, em face da urgência em desenvolver os incipientes cursos técnicos secundários e lançar outros em condições que permitam, pelo menos, uma razoável qualidade à partida (e uma constante melhoria no futuro), passa-se à consideração do ensino da Química no 12. ${ }^{\circ}$ ano - via do ensino superior.

\section{Química no $12 .^{\circ}$ ano}

As principais criticas feitas, porventura unanimemente, ao actual ensino da Química no $12 .^{\circ}$ ano podem reunir-se em duas categorias:

A. No plano dos conteúdos e métodos

O corpo de conhecimentos efectivamente ministrado é desiquilibrado, com manifesto prejuízo para certos aspectos fundamentais das transformaçōes da matéria (reacções de compostos orgânicos, introdução à termodinâmica química, cinética química, transformaçōes nucleares), e, muito importante, não motivado nem apoiado por qualquer trabalho laboratorial realizado pelo aluno, nem sequer, em via de regra, por demonstração experimental feita pelo professor.

O desenvolvimento das capacidades de aplicação de conhecimento e informação dada em situações novas e em exercícios numéricos é insuficiente, assim como o é o desenvolvimento da capacidade do aluno aprender por si próprio, das atitudes perante o saber e dos seus métodos de estudo.

B. No plano da avaliação do aproveitamento escolar do aluno

A intervenção da informação do professor na determinação da classificação final, em princípio uma medida correcta, tem, infelizmente, conduzido a várias situações de escândalo e, no mínimo, a uma demasiada disparidade de critérios classificativos. Escândalo igualmente se tem verificado com a realização das provas finais em escolas não-idóneas ou com professores-vigilantes não-idóneos para o efeito.

Acrescem casos de insuficiente competência na correcção e classificação das provas nacionais e uma ausência quase total de coordenação no processo classificativo. Daí o anormalmente elevado número de recursos bem sucedidos.

Múltiplos são os factores próximos que determinam esta situação e que se consideram implícitos em algumas das medidas correctivas que a seguir se propð̃em:

A. No plano dos conteúdos e métodos

1. Aumentar de 4 para 5 ou 6 horas o tempo lectivo semanal, se não no prazo de 1 , ao menos de 2 anos, a fim de incluir prática laboratorial e o cumprimento de um conjunto mais equilibrado de matérias.

2. Reformular o programa original, em conformidade, e em vista da experiência entretanto acumulada.

3. Entretanto, fazer aplicar um programa mínimo mais equilibrado (e não por eliminação de matéria a partir de certo capítulo num programa inicial equilibrado no seu todo*) e que inclua, pelo menos, algumas demonstraçðes experimentais exequíveis em qualquer escola.

4. Actuar urgentemente ao nível do ensino-aprendizagem da Química nos anos anteriores, desde o 8..$^{\circ}$, e da Lingua Portuguesa e da Matemática, desde o início da escolaridade**.

5. Intensificar acções de aperfeiçoamento de professores do $12 .^{\circ}$ ano, em articulação com o ensino superior.

6. Requerer dos professores apelo ao crescente trabalho individual dos alunos, não obstante a maior escolaridade semanal prevista acima, em vista do ensino superior que esperam.

7. Início oportuno das aulas e compensação dos efeitos das eventuais faltas de professores, com orientação do trabalho dos alunos por outros professores da mesma escola (adequadamente compensados por isso).

\footnotetext{
- Departamento de Química, Universidade de Coimbra
}

* Que é o que sucede neste momento.

** Em particular, ponderar seriamente a reposição das C. Físico-

-Químicas no $7 .^{\circ}$ ano e disciplinar a repartição do tempo a devotar à Física e à Química em cada ano do $80^{\circ}$ ao $11 .^{\circ}$. 


\section{B. No plano da avaliação do aproveitamento escolar dos alunos}

8. Redução, para cerca de $15 \%$, da contribuição da informação do professor para a nota final do $12 .^{\circ}$ ano (medida que acaba de ser tomada pelo Ministério da Educação).

9. Intervenção da Universidade no processo relativo ao exame final, de modo a que o exame terminal no ensino secundário seja também decisório (juntamente com a informação referida em 8.) sobre o ingresso no ensino superior, sem necessidade de novas provas (como as de admissão de que se tem falado).

10. Cuidada elaboração dos pontos por uma equipa constituída por 2 professores do ensino superior e 2 professores do ensino secundário, todos de reconhecida competência para o efeito, com mais vasta correspondência com os objectivos do programa (incluindo questōes que procurem averiguar sobre a realização do trabalho experimental) e, quiçá, maior exigência.

11. Maior cuidado na selecção das escolas onde se realizam as provas e dos professores vigilantes, com eventual redução do número daquelas, e realização das provas, sempre que possível, em estabelecimentos de ensino superior.

12. Optimizar o processo de correcção e classificação das provas, por exemplo nos moldes seguintes:

a. Convidar os professores a enviarem, por escrito, críticas e comentários a cada ponto, até 5 dias após a realização deste.

b. Reunir 20 professores ( 15 do ensino secundário e 5 do ensino superior) previamente seleccionados (ou indicados pelas escolas, em regime rotativo) e os 4 responsáveis pela elaboração do ponto, como coordenadores do processo de correcção, para ajuste de critérios (tendo em vista as críticas e comentários referidos em a.) e atribuindo a cada professor apenas uma questão a classificar.

c. Proceder à correcção e classificação por cada um dos 20 professores, em contacto frequente com os coordenadores, de preferência reunidos durante alguns dias (estimado em $\mathrm{n}=\mathrm{n} .^{\circ}$ de provas $/ 500$ ) num mesmo local.

13. Com um processo como este também as razões para recursos se reduzirão grandemente, de tal modo que, a admitirem-se, deveriam ser fortemente desencorajados (por exemplo por depósito de caução não reembolsável em caso de insucesso).

\section{Química no $1^{\circ}$ ano do ensino superior}

Aqui, uma das principais insatisfaçôes dos professores parece decorrer da presença de alunos sem o $12 .^{\circ}$ ano de Química em cursos em que a Química é uma das áreas, por vezes a fundamental, e isto em turmas com outros alunos do mesmo curso e que frequentaram esse ano. E queixam-se também de uma generalizada má preparação trazida pelos alunos, quer em conhecimentos quer em atitudes.

Por parte dos alunos, as críticas parecem ir sobretudo para a velocidade, que consideram excessiva, com que as matérias são leccionadas, insuficiente apoio dos professores em certos casos, deficiência (se não mesmo ausência) de coordenação de programas das várias disciplinas e de coordenação de horários e calendários de provas de avaliação respectivas.

À análise exterior não pode, enfim, furtar-se o facto de o rendimento escolar ser muito reduzido.
Esta situação não é, evidentemente, exclusiva da Quimica, Que fazer?

1. A heterogeneidade de preparação dos alunos no mesmo curso resulta da versatilidade na escolha do curso superior, quase independente das disciplinas frequentadas no $12 .^{\circ}$ ano, imposta por um excessivo desajustamento entre a procura e a oferta de vagas no ensino superior. Parece, porém, possível manter esta versatilidade e ajustar melhor o elenco de disciplinas do $12 .^{\circ}$ ano aos vários cursos. Trata-se de definir, para cada curso, uma disciplina nuclear (Química para cursos de Química e Engenharia Química), uma sub-nuclear a escolher pelo aluno de um leque de 2 ou 3 (Física, Matemática, Biologia, no caso de Química) e uma de opção, de um outro leque que inclua as que restam do leque anterior depois de escolhida a sub-nucelar: Isto permitiria, ainda, que o mesmo elenco de disciplinas desse acesso a vários cursos, pois sub-nuclear para uma seria nuclear para outro, etc. (e proporcionaria critérios de desempate mais racionais, recorrendo-se, para uma mesma média, sucessivamente à nota da nuclear e da sub-nuclear).

2. Para os (assim, já menos) alunos numa cadeira de Química de $10^{\circ}$ ano que não tenham frequentado esta disciplina no $12 .^{\circ}$ ano, dever-se-ia organizar um curso intensivo de homogeneização antes do início do ano lectivo e/ou manter aulas tutorais específicas ao longo do ano.

3. Enquanto se aguarda que as melhorias introduzidas no ensino secundário tenham reflexo no aproveitamento no ensino superior e que se diminua o desencontro entre o curso prioritariamente desejado e aquele em que o aluno é muitas vezes colocado, as instituições de ensino superior têm muito a corrigir no capítulo pedagógico. Assim,

a. São necessárias acçð̃es de coordenação curricular e, também, de coordenação da avaliação do aproveitamento escolar dos alunos, de forma a que, sem prejuízo dos objectivos classificadores e de incentivo ao trabalho metódico que a avaliação tem, ela não pertube negativamente a própria aprendizagem firme e serena em cada disciplina;

b. Considerando que parte dos males decorre de uma excessiva dispersão escolar em cada semestre, não sempre em termos de áreas mas de disciplinas autónomas, com seus métodos e esquemas de avaliação próprios, há que actuar no sentido de se reorganizar o currículo geral de cada semestre em 3 áreas disciplinares, num total de 21-24 horas por semana, com avaliação única em cada área, intensificando-se simultaneamente a real aprendizagem individual pelo aluno;

c. Com vista a facilitar a adaptação dos alunos ao ensino superior e assim contribuir para a melhoria do rendimento escolar, há que estabelecer apoios pedagógicos no $1 .^{\circ}$ ano, em regime tutorial ou equivalente. E minha convicção que estas medidas são exequiveis a curto prazo, e que teriam imediatos beneficios. É certo que supðem algumas mudanças e um esforço adicional por parte dos docentes do ensino superior; mas os benefícios previstos justificam-nos plenamente.

Entretanto, as alteraçðes à situação do $12 .^{\circ}$ ano, acima propostas, também seriam determinantes.

A médio prazo, aposta-se em melhorias do ensino-aprendizagem da Química a partir do $8 .^{\circ}$ ano (o projecto "Química para Ti", do Departamento de Química da Universidade de Coimbra com os livros do $8 .^{\circ}$ e $9 .^{\circ}$ anos e Guia do Professor já publicados, procura contribuir para isso). 